\title{
The Prevalence of Klebsiella Species Causing Urinary Tract Infections in Murtala Muhammad Specialist Hospital, Kano, Nigeria
}

\author{
Hamza Sule*, Abdulhadi Sale Kumurya \\ Department of Medical Laboratory Science, Faculty of Allied Health Sciences, Bayero University, Kano, Nigeria \\ Email address: \\ sule.hamza@yahoo.com (H. Sule) \\ ${ }^{*}$ Corresponding author
}

\section{To cite this article:}

Hamza Sule, Abdulhadi Sale Kumurya. The Prevalence of Klebsiella Species Causing Urinary Tract Infections in Murtala Muhammad Specialist Hospital, Kano, Nigeria. American Journal of Biomedical and Life Sciences. Vol. 4, No. 2, 2016, pp. 11-15. doi: $10.11648 /$ j.ajbls.20160402.11

Received: February 13, 2016; Accepted: February 23, 2016; Published: March 16, 2016

\begin{abstract}
Urinary tract infections (UTIs) are among the most commonly encountered infections, both in the community and in hospitals. The study investigated the Prevalence of Klebsiella species among patients suspected of UTI in Murtala Muhammad Specialist Hospital, Kano, Nigeria. Two hundred urine specimens of patients comparing of 135(67.5\%) outpatients and 65(32.5\%) inpatients and classified into 125(62.5\%) females and 75(37.5\%) males were bacteriologically evaluated. A total of $61(30.5 \%)$ yielded significant growth on culture of which 50(25\%) were from females and 11(5.5\%) from males. The age distribution of the patients with significant bacterial growth showed that patients within the age group of 21-30 years had the highest (UTI) cases of $33(16.5 \%)$ but those within the age group of less or equal to 10 years and those within the 51 to 60 years age bracket had 3(1.5\%) UTI cases each. Of the uropathogens isolated, Escherichia coli was the most frequent organism responsible for UTI with $29((14.5 \%)$, followed by Klebsiella species with $16(8.0 \%)$. Other organisms isolated were Staphylococcus species 9(4.5\%), proteus species 5(2.5\%) and Pseudomonas species 2(1.0\%) respectively. The speciation of Klebsiella species isolated 'showed that 14(7.0\%) were Klebsiella pneumoniae and 2(1.0\%) were Klebsiella oxytoca. The antibiotic susceptibility testing for Klebsiella species isolates showed Ofloxacin as the best drug of choice with all the 16 isolates susceptible to Ofloxacin but at the same time all were resistant to ampicillin.
\end{abstract}

Keywords: Prevalence, Urinary Tract Infections, Klebsiella, Kano

\section{Introduction}

The Urinary tract is the name given to the internal organs that collect, store and expel urine from the body, while the urinary tract infection (UTI) can be defined as condition in which bacteria are multiplying and attacking the urinary tract regardless of the position along the tract. It has been observed that untreated asymptomatic bacteriurea, if not treated has the tendency of leading to cystitis and/or pyelonephritis, which will cost more to treat and cause more havoc [1]. Symptoms associated with urinary tract infection include - pain or burning (discomfort) sensation at urinating; a feeling of urgency at urination; cramps or pain in the lower abdomen; the need to urinate more often than usual; urine that looks turbid and has foul smell; pain, pressure or tenderness in the area of the bladder and when bacteria spread to the kidneys, there can be back pain, chills, fever, nausea and vomiting [2]. UTI has become the most common hospital-acquired infection, accounting for as many as $35 \%$ of nosocomial infections, and it is the second most common cause of bacteraemia in hospitalized patients [3, 4, 5]. Urinary tract infections (UTIs) are common among inpatients and outpatients, ranking second only to respiratory infections. In the United States, it is estimated, from surveys of office practices, hospital-based clinics and emergency departments that UTIs account for over eight million cases annually and more than 1 million hospitalizations, with an overall annual cost in excess of $\$ 1$ 
billion $[6,7,8]$. Factors that predispose an individual to UTI include: (a) Stasis; a major cause of UTI during pregnancy. (b) Obstruction of the flow of urine, which could be caused by stone. (c) Presence of foreign body such as in-dwelling bladder catheter. (d) A decrease in general body resistance as observed in malnourished individuals, use of immunosuppressive drugs and disease conditions e.g. diabetes $[9,10]$. Females are believed to be more affected than males except at the extremes of life, because bacteria can reach the bladder more easily in women, partially due to the short and wider female urethra, and its proximity to the anus [11,5]. According to [7] an estimated $40 \%$ of women reported having had a UTI at some point in their life time. Urinary tract infections (UTIs) are a major cause of morbidity worldwide. In a study done in other parts of the world on outpatient infections, UTIs were the second most common diagnosis after upper respiratory tract infections [28].

\section{Materials and Methods}

\subsection{Study Area}

The study was carried out in Kano metropolis (the capital city of Kano State, Nigeria). The state was created on May 27, 1967 from part of the then Northern region. It is known for high commercial activities as the second largest industrial center in Nigeria and the largest in Northern Nigeria. Commercial activities in Kano first developed with the establishment of Kurmi market by the Emir of Kano Muhammadu Rumfa, in the 16th Century. The people in the state also had the history of large scale agricultural activities leading to groundnut pyramid, which though not in existence now, but still remain part of the state's symbols. People of Kano are predominantly Hausa/Fulani and practice Islam as their religion.

\subsection{Specimens Collection and Processing}

A total of two hundred patients whom were clinically suspected of urinary tract infections in Murtala Muhammad Specialist Hospital, Kano were given sterile universal bottles and instructed on how to produce a clean catch early morning mid steam urine. All samples submitted were processed immediately, but where delay was anticipated the samples were kept in the fridge at $4^{\circ} \mathrm{C}$ before processing. Macroscopy was done before inoculations onto Cysteine lactose electrolyte deficient agar and Chocolate agar. After culturing about $10 \mathrm{mls}$ of each sample was spun in the centrifuge and a drop of the deposit of each was put on a clean grease free slide and examined under light microscope using $10 \mathrm{x}$ and $40 \mathrm{x}$ objectives for bacteria, pus cells, RBCs, yeast cells etc. Part of these deposits were also used for direct gram staining. All inoculated samples were incubated at $37^{\circ} \mathrm{C}$ for 24 hours $[12,13]$. Observed colonies were identified using colonial morphology and biochemical characteristics. Discrete colonies (pure culture) were sought for by subculture onto McConkey agar and incubated at $37^{\circ} \mathrm{C}$ for 24 hours.

\subsection{Antibiotic Susceptibility Testing}

The pattern of susceptibility of the isolates to various antibiotics was determined according to modified KirbyBauer disc diffusion method [14]. The inoculated plates carrying the antibiotic discs were incubated at $37^{\circ} \mathrm{C}$ for 24 hours [13].

\subsection{Statistical Analysis}

Statistical analysis was carried out using computer database software from the statistical package from social sciences (SPSS version 16) to generate frequency distribution and percentage prevalence scores of the various parameters. Descriptive analysis of the percentages of continuous variables was reported.

\section{Results}

Two hundred specimens of patients suspected of urinary tract infections (UTI), consisting of 135(67.5\%) from outpatients and $65(32.5 \%)$ from inpatients were used. Out of the total, $75(37.5 \%)$ and $125(62.5 \%)$ were males and females respectively (Table 1).The culture yielded a total of $61(30.5 \%)$ significant bacteriuria of which $50(25 \%)$ were from females and $11(5.5 \%)$ from males (Table 2$)$. The significant growth of specimens in relation to age groups showed that patients within the age group of 21-30 years has the highest growth $33(16.5 \%)$ while patients within the age group of $\leq 10$ years and those of 51-60 had 3(1.5\%) growth each (Table 3 ). The prevalence of the organisms isolated in the study showed that close to half of the total number of isolates recovered was Escherichia coli with the prevalence of $29(14.5 \%)$. This was followed by Klebsiella species, Staphylococcus species, Proteus species and Pseudomonas species with prevalence of $16(8.0 \%)$, $9(4.5 \%), 5(2.5 \%)$ and $2(1.0 \%)$ respectively (Table 4$)$. The occurrence of Klebsiella Species among the age groups of the patients in the study showed that, patients within the age group of 21-30 years had the highest prevalence of $7(3.5 \%)$ in which $2(1.0 \%)$ were males and $5(2.5 \%)$ were females (Table 5). Out of the 16 Klebsiella species isolated, $14(7.0 \%)$ were biochemically identified as Klebsiella Pneumoniae and 2(1.0\%) were Klebsiella oxytoca (Table 6). All the 16 Klebsiella species isolated were susceptible to Ofloxacin while $15(93.75 \%)$ and $14(87.5 \%)$ were susceptible to nitrofurantoin and Nalidixic acid respectably. The study showed that all the Klebsiella species were resistant to ampicillin (Table 7).

Table 1. Distribution of patients suspected of UTI in relation to gender.

\begin{tabular}{llll}
\hline Group & Number (\%) & Female (\%) & Males (\%) \\
\hline Outpatients & $135(67.50)$ & $100(50.00)$ & $35(17.50)$ \\
Inpatients & $65(32.50)$ & $25(12.50)$ & $40(20.00)$ \\
Total & $200(100)$ & $125(62.50)$ & $75(37.50)$ \\
\hline
\end{tabular}


Table 2. Distribution of specimens with significant growth on culture.

\begin{tabular}{llll}
\hline Group & Females (\%) & Males (\%) & Total (\%) \\
\hline Outpatients & $40(20.00)$ & $6(3.00)$ & $46(23.00)$ \\
Inpatients & $10(20.00)$ & $5(2.50)$ & $15(7.500)$ \\
Total & $50(25.00)$ & $11(5.50)$ & $61(30.50)$ \\
\hline
\end{tabular}

Table 3. Significant bacteriuria in relation to age.

\begin{tabular}{lll}
\hline Age Group (Years) & Number Examined (\%) & Number of Significant Growth (\%) \\
\hline$\leq 10$ & $20(10.00)$ & $3(1.50)$ \\
$11-20$ & $24(12.00)$ & $6(3.00)$ \\
$21-30$ & $79(39.50)$ & $33(16.50)$ \\
$31-40$ & $35(17.50)$ & $11(5.50)$ \\
$41-50$ & $20(10.00)$ & $5(2.50)$ \\
$51-60$ & $14(7.00)$ & $3(1.50)$ \\
$\geq 61$ & $8(4.00)$ & $0(0.00)$ \\
Total & $200(100.00)$ & $61(30.5)$ \\
\hline
\end{tabular}

Table 4. Prevalence of uropathogens isolated from the specimens.

\begin{tabular}{lll}
\hline Organisms & Number of Specimens & Percentage (\%) \\
\hline Escherichia coli & 29.00 & 14.50 \\
Klebsiella species & 16.00 & 8.00 \\
Staphylococcus species & 9.00 & 4.50 \\
Proteus species & 5.00 & 2.50 \\
Pseudomonas species & 2.00 & 1.00 \\
Total & 61.00 & 30.50 \\
\hline
\end{tabular}

Table 5. Occurrence of Klebsiella species in relation to age and sex.

\begin{tabular}{llll}
\hline Age Group & Male & Female & Total \\
\hline$\leq 10$ & $0(0.00)$ & $1(0.50)$ & $1(0.50)$ \\
$11-20$ & $1(0.50)$ & $1(0.50)$ & $2(1.00)$ \\
$21-30$ & $2(1.00)$ & $5(2.50)$ & $7(3.50)$ \\
$31-40$ & $1(0.50)$ & $2(1.00)$ & $3(1.50)$ \\
$41-50$ & $1(0.50)$ & $1(0.50)$ & $2(1.00)$ \\
$51-60$ & $0(0.00)$ & $1(0.50)$ & $1(0.50)$ \\
$\geq 61$ & $0(0.00)$ & $0(0.00)$ & $0(0.00)$ \\
Total & $5(2.50)$ & $11(5.50)$ & $16(8.00)$ \\
\hline
\end{tabular}

Table 6. Speciation of Klebsiella species isolated.

\begin{tabular}{lll}
\hline Klebsiella species & Number isolated & Percentage (\%) \\
\hline Klebsiella pneumoniae & 14.00 & 7.00 \\
Klebsiella oxytoca & 2.00 & 1.00 \\
Total & 16.00 & 8.00 \\
\hline
\end{tabular}

Table 7. Susceptibility pattern of the Klebsiella isolates to Antimicrobial agents.

\begin{tabular}{lll}
\hline Antibiotics & $\begin{array}{l}\text { Number of susceptible } \\
\text { isolates }\end{array}$ & $\begin{array}{l}\text { Percentage of } \\
\text { susceptible isolates }\end{array}$ \\
\hline Nalidixic acid & 14.00 & \\
Nitrofurantoin & 15.00 & $(87.50)$ \\
Ofloxacin & 16.00 & $(93.75)$ \\
Colistin phosphate & 13.00 & $(100.00)$ \\
Gentamycin & 13.00 & $(81.25)$ \\
Streptomycin & 8.00 & $(81.25)$ \\
Cotrimoxazole & 5.00 & $(50.00)$ \\
Ampicillin & -0.00 & $(31.00)$ \\
\hline
\end{tabular}

\section{Discussion}

UTI is one of the most common infectious diseases [15]. Escherichia coli and Klebsiella species have been reported to be the most common organisms causing UTI. The study on Klebsiella species was carried out on specimens of 200 patients suspected of urinary tract infection of which $135(67.50 \%)$ were out-patients and $65(32.5 \%)$ were inpatients. The overall prevalence of the uropathogens was $61(30.5 \%)$ in the study which is in agreement with work of [16] that used 200 urine samples and got $70(35 \%)$ prevalence of UTI. But the study of [17] which also used 200 urine samples had a lower prevalence of $21 \%$. Females were observed to have higher cases of UTI than the males with $50(25.00 \%)$ as the significant growth recorded. This conformed to work [18] with prevalence of $46(34.4 \%)$ and $17(12.7 \%)$ for females and males respectively. The other work of [19] recorded infection rates of 68(30.2\%) and $49(21.8 \%)$ for females and males respectively.

The age group with highest prevalence was 21-30 with $33(16 \%)$ out of the $79(39.5 \%)$ specimens examined in the group which is in agreement with the findings [20] where patients with the age group of 21-25 had the highest infection rate of 20(51.3\%) against the other groups used. Escherichia coli was the predominant uropathogens with $29(14.50 \%)$ of the total $61(30.50 \%)$ isolates, followed by Klebsiella species $16(8.00 \%)$ isolates, then Staphylococcus species, Proteus species and Pseudomonas species with 9(4.50\%), 5(2.50\%) and $2(1.00 \%)$ isolates respectively. This compares favourably with Escherichia coli 55(48.7\%) followed by Klebsiella species $27(23.9 \%)$ in the study of [21]; Escherichia coli 323(54.5\%), Klebsiella species 127(21.5\%) in the study of [22]. But the study contrasts the work titled Klebsiella has taken the lead by [23] with relative prevalence of 93(33.3\%) and 90(32.3\%) for Klebsiella species and Escherichia coli respectively and that of [24] with prevalence of Klebsiella species (26\%) followed by Escherichia coli $(19 \%)$. Out of the different uropathogens isolated in this 
study, Klebseiella species encountered were Klebsiella pneumoniae and Klebsiella oxytoca. Same species were also isolated by [25] with six (6) Klebsiella Pneumoniae and only one (1) Klebsiella oxytoca isolate as against the fourteen (14) and two (2) Klebsiella Pneumoniae and Klebsiella oxytoca isolated respectively in this study. [26] also isolated similar species in urine samples they used in their study but with higher frequency of 33 and 19 for Klebsiella pneumonia and Klebsiella oxytoca respectively. One thing that cross wised all the three studies was that Klebsiella pneumonia was the predominant isolate in all the studies.

The antimicrobial susceptibility pattern of Klebsiella species isolated in the study revealed Ofloxacin and Nitrofurantoin to be the most promising drug of choice for the treatment of UTI. According to the finding [27], ofloxacin also proved effective against UTI isolates with efficacy of (79.8\%) but second to Gentamycin (80.6\%). Ampicillin and cotrimoxazole had the lowest efficacy of $(8.0 \%)$ and $(21.0 \%)$ respectively, in this study.

\section{Conclusion}

Conclusively, an overall prevalence of $16(8.0 \%)$ of Klebsiella species was observed in this study. Females had a $4-18$ fold increase risk of having UTI, and Klebsiella species were the second predominant isolates causing UTI in Kano, Nigeria. Although the flouroquinolones were the most active antibacterial agents, prudent use of antibiotics is advocated.

\section{Acknowledgement}

We thank the management of Murtala Muhammad Specialist Hospital for their ethical permission to carry out the work in their facility. Our appreciation also goes to the entire staff of Medical Microbiology Laboratories of the Hospital for their valuable contributions and assistance in the collection of the urine specimens.

\section{Ethical Issues}

Ethical permission was obtained from the Ethical Committee of Murtala Muhammad Specialist Hospital.

\section{References}

[1] Sheiner, E. Mazor-Drey, E. and Levy, A. (2009). "Asymptomatic bacteriaria during pregnancy," J. Matem Fetal Neonatal Med. 22: 423-427.

[2] John Delzell, J. and Michael, L.(2000). "Urinary tract infection during pregnancy," Am Fam, Physician. 61:713-720.

[3] Weinstein, M. P. Towns, M. L. Quartey, S. M. (1997). The clinical significance of blood cultures in the 1990s: A prospective comprehensive evaluation of the microbiology, epidemiology and outcome of bacteraemia and fungemia in adults. Clin. Infect. Dis. 24:584-602.
[4] Stamm, W. E. (2002). Scientific and Clinical Challenges in the Management of Urinary Tract Infections. Ame. J. Med. 113: $1 \mathrm{~s}-4 \mathrm{~s}$.

[5] Kolawole, A. S. Kolawole, O. M. Kandaki-Olukemi, Y. T. Babatunde, S. K. Durowade, K. A. Kolawole, C. F. (2009). Prevalence of urinary tract infections (UTI) among patients attending Dalhatu Araf Specialist Hospital, Lafia, Nasarawa State, Nigeria. Int. J. Medicinal Med. Sci. 1(5):163-167.

[6] Patton, J. P. Nash, D. B. Abrutyn, E. (1991). Urinary tract infection: economic considerations. Med. Clin. North Am. 75:495-513.

[7] Kunin, C. M. (1994). Urinary tract infections in females. Clinc. J. Infec. Dis. 18:1-12.

[8] Aiyegoro, O. A. Igbinosa, O. O. Ogunmwonyi, I. N. Odjadjare, E. E. Igbinosa, O. E. Okoh, A. I (2007). Incidence of urinary tract infections (UTI) among children and adolescents in Ile-Ife, Nigeria. Afr. J. Microbiol. Res. 013-019.

[9] Olowu, W.A. (1996). The office of Urinary Tract Infection and Vesicoureteral reflux in children, USA. Urol. Clin. North Am. 25 (4): 25-34.

[10] Foxman B, Brown P. (2003). Epidemiology of urinary tract infections: transmission and risk factors, incidence, and costs. Infect Dis Clin North Am. 17(2): 227-24.

[11] Ebie, M. Y. Kandakai-Olukemi, Y. T. Ayanbadejo, J. and Tanyigna, K. B. (2001). Urinary Tract Infections in a Nigerian Military Hospital, Nigerian. J. Microbiol; 15(1):31-37.

[12] Mackey and McCartney, (1996). Tropical Medical Micrbiology $14^{\text {th }}$ ed. Churchill Livingstone. London. Pp. 978.

[13] Cheesebrough, M. (2000). Distric Laboratory Practice in Tropical Countries Low Price ed. Chambridge University Press. Pp. 434.

[14] Kirby, W. Bauer, A. Sherris, J. and Truck, M. (1966). "Antibiotic susceptibility testing by a standardized single disc method," Am. J. Clin. Path. 45:493-496.

[15] Hooton, T. M. (2000). Pathogenesis of urinary tract infection: an update. J Antimicrob Chemother. 46:S1-S.

[16] Kais, K. Ghanima, (2006). Development of resistance of some Klebsiella species isolated locally from UTI to some Beta Lactam antibiotics. UM-Salama Science J. 3(4):694-701.

[17] Raphael, M. M. Moghene, E. B. Emmanuel, E. O. Stephen, A. E. Onyinye, J. U. (2015). Prevalence of Urinary Tract Infections (UTI) Among Pregnant Women in University of Benin Teaching Hospital (UBTH) Benin City, Nigeria. Journal of Asian Scientific Research. 5(4):198-204.

[18] Ojo, D. A. Akpan, I. and Mafiana, C. F. (2007). Asymptomatic and symptomatic urinary tract infection in a Nigerian community. asset Series B 6(1):32-39.

[19] Ojo, D. A, Osuolale, K. O. and Mafiana, C. P. (2004). Prevalence of urinary tract infection among students in a Nigerian University. Proceedings of int'l conference on science and national dev.25 $5^{\text {th }}-28$ Oct. (2004).

[20] Obiogbolu, C. H. Okonko, I. O. Anyamere, C. O. Adedeji, A. O. Akanbi, A. O. Ogun, A. A. Ejembi, J. And faleye, T. O. C. (2009). Incidence of Urinary Tract Infections (UTIs) Among Pregnant Women in Akwa Metropolis, Southeastern Nigeria. Scientific Research and Essay 4(8):820-824. 
[21] Alex, B. Peter, M. S. Johnson, N. B. George, A. K. RichardKwabena, D. E. Patrick, A. Gyasi, O. Dennis, P. (2012). Asymptomatic urinary tract infections in pregnant women attending antenatal clinic in Cape Coast, Ghana. E3 Journal of Medical Research. 1(6):074-083. Available online at $\mathrm{http} / / / \mathrm{www} . \mathrm{e} 3$ journals.org.

[22] Namratha, W. N. (2015). Profile of Urinary Tract Infection and Quinolone Resistance among Escherichia coli and Klebsiella species isolates. Int. J. Curr. Microbiol. App. Sci 4(7):749-756.

[23] Osazuwa, F. Mordi, R. M. Osazuwa, E. Taiwo. S. S. Alli, O. A. T. Ogbolu, D. O. Akanni, E. O. Anukam, K. C. (2010). Klebsiella has taken lead among uropathogens in University of Benin Teaching Hospital, Benin City, Nigeria-An observation. New York Science Journal. 3(11):61-64.

[24] Agbagwa, O. E. Ifeanacho, Emeka, J. U. (2015). The Prevalence of UTI Pathogens in Urine Specimen Obtained from a Hospital in Rivers State Nigeria. Journal of Microbiology Research 5(5):143-148.
[25] Ekrem, K. Dyar musadaq, S. Daham yousif, A. Dlzar bayz, R. and Faisal sharaf, Y. (2015). Identification of the bacterial types that cause urinary tract infection and antimicrobial susceptibility in Erbil, Iraq. Sky Journal of Microbiology Research. 3(1):011-014.

[26] Acheampong, D. O. Boamponsem, L. K. and Feglo, P. K. (2011). Occurrence and species distribution of Klebsiella Isolates: A case study at Komfo Anokye teaching hospital (Kath) in Ghana. Advances in Applied Science Research. (4):187-193 www.pelagiaresearchlibrary.com.

[27] Manikandan, C. and Amsath, A. (2013). Antibiotic susceptibility pattern of Klebsiella pneumoniae isolated from urine samples Int. J. Curr. Microbiol. App.Sci 2(8):330-337.

[28] Avci, I. Y. Kilic, S. Acikel, C. H. (2006). Outpatient prescription of oral antibiotics in a training hospital in Turkey: Trends in the last decade. J Infect. 52(1):9-14. 